\title{
AVALIAÇÃO DE CICLO DE VIDA DE UM REATOR EM BATELADAS SEQUENCIAIS
}

\author{
Patrícia Braun, Bacharel Eng. Sanit. e Amb. (UFSC) \\ Guilherme M. Zanghelini, Msc. Eng. Sanit. e Amb. (UFSC) \\ Sebastião Roberto Soares, Dr. Gestão Trat. de Resíduos (INSA DE LYON)
}

\section{INTRODUÇÃO}

Os sistemas de tratamento de efluentes são utilizados há anos para reduzir os riscos de contaminação e os impactos no ambiente. Os investimentos em pesquisa na área resultaram em novas tecnologias, bem como no aprimoramento daquelas mais antigas. Porém, os esforços geralmente se limitam a atingir maiores eficiências, deixando de lado os impactos causados pelo próprio sistema de tratamento.

Por este motivo, os profissionais da área passaram a incorporar novos critérios e abordagens na escolha das técnicas disponíveis. Uma das formas de avaliar os impactos de maneira global, é através da Análise de Ciclo de Vida $(A C V)$. A ACV é uma metodologia de apoio à tomada de por um processo, produto ou serviço (GUINEÉ et al, 2011). Os primeiros estudos de ACV aplicados ao tratamento de efluentes são da década de 90 (COROMINAS et al., 2013).

\section{DESENVOLVIMENTO}

O sistema de tratamento avaliado pertence ao Laboratório de Efluentes Líquidos e Gasosos (LABEFLU) da Universidade Federal de Santa Catarina (UFSC). Consiste em um Reator em Bateladas Sequenciais com Grânulos (RBSG), com capacidade de tratar 55 litros de efluente bruto por ciclo. Informações adicionais sobre o funcionamento do reator podem ser encontradas em Daudt (2015).

A unidade funcional (UF) estabelecida é $1 \mathrm{~m}^{3}$ de esgoto tratado, considerando que o sistema garante eficiência mínima para atender os padrões de lançamento estabelecidos pela legislação vigente. Três etapas foram consideradas na fronteira do sistema: construção, operação e fim de vida. Os dados primários são oriundos de Daudt (2015).

O software utilizado para realizar a Avaliação de Impacto de Ciclo de Vida (AICV) é o SimaPro. O método escolhido para caracterização e normalização foi o CML 2000. O estudo direcionou a análise para o aquecimento global (AG), acidificação (AC), depleção da camada de ozônio (DCO), eutrofização (EU) e demanda acumulada de energia (DAE).

\section{RESULTADOS}

A Figura 1 apresenta o fluxograma com as entradas e saídas de cada uma das etapas elementares. A linha tracejada indica a fronteira do sistema.

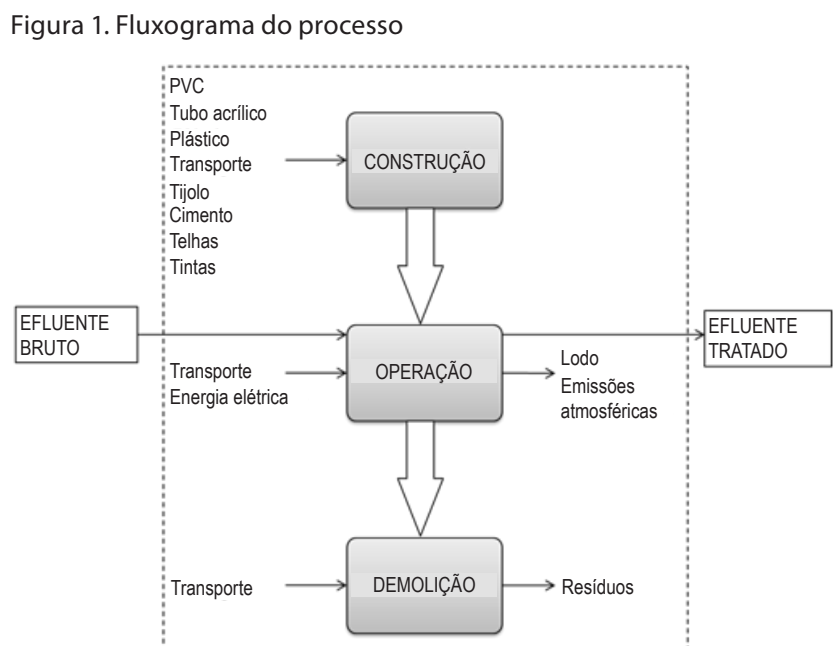

A Figura 2 apresenta os resultados para as categorias definidas no escopo. Conforme pode ser notado, em todas elas, predomina a etapa de operação variando entre, aproximadamente, $75 \%$ a $86 \%$ de contribuição. O maior responsável pelos impactos nesta fase é o consumo de energia o que o torna o principal gargalo do sistema.

A construção apresentou maior impacto nas categorias de depleção da camada de ozônio e demanda acumulada de energia, com $30 \%$ e $23 \%$ respectivamente (Figura 2). A etapa de demolição se mostrou desprezível em relação às demais (construção e operação), sendo que a maior contribuição ocorre para a depleção da camada de ozônio com 2,89\% do total de impactos. Nas demais categorias a demolição representa menos de $1 \%$.

\section{CONCLUSÕES}

O consumo de energia do processo foi um dos maiores responsáveis pelos impactos ambientais nas categorias avaliadas. Mesmo em categorias de impacto como o 
Figura 2. Etapas do ciclo de vida do sistema de tratamento (resultados normalizados internamente).

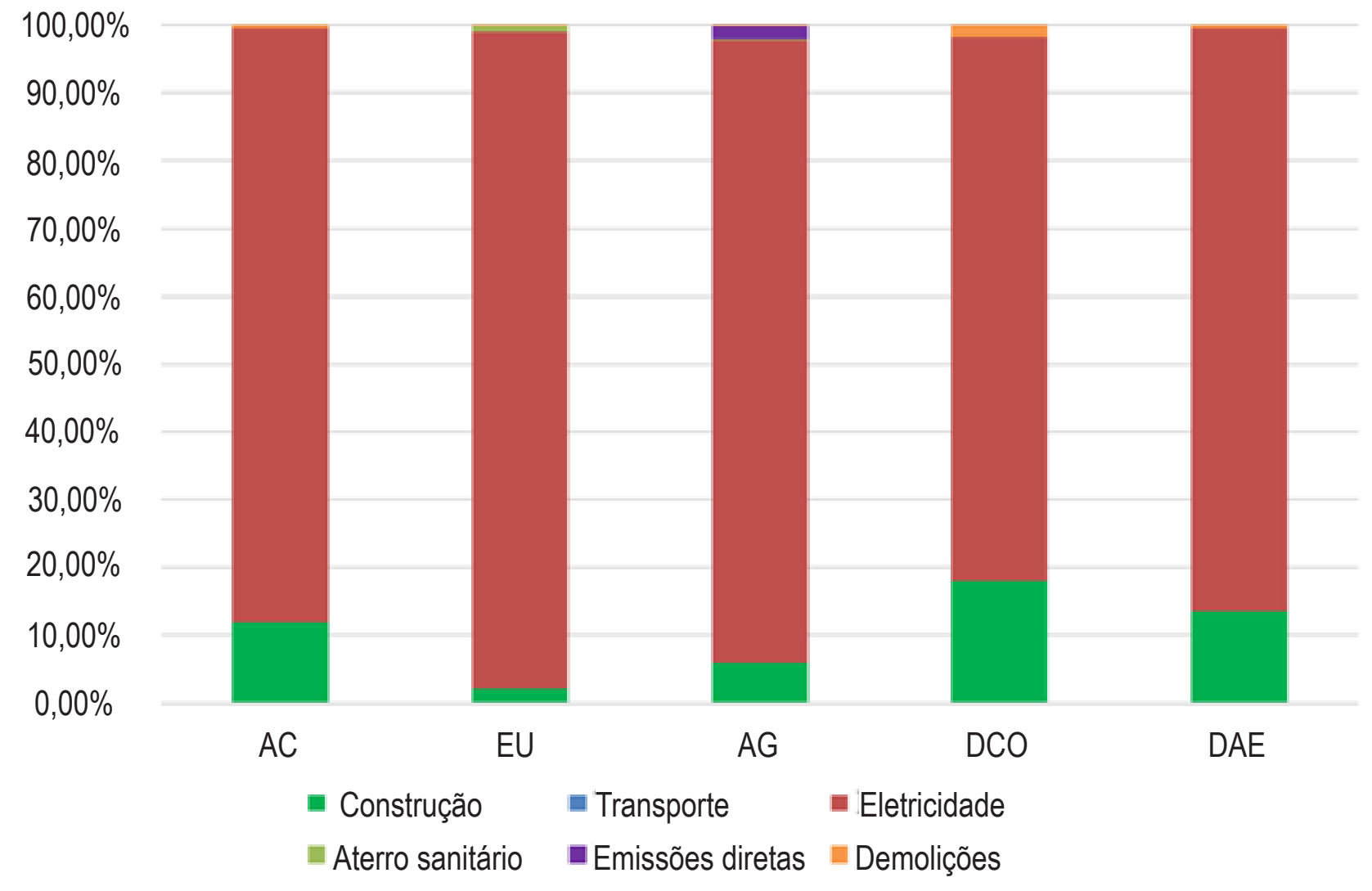

Aquecimento Global, onde as emissões diretas de $\mathrm{CO} 2 \mathrm{e}$ N2O-N do tratamento apresentavam potencial aparente de geração de impacto, a ACV demonstrou que os esforços de melhoria devem focar em outras frentes. Dessa forma, recomenda-se aprofundar os estudos considerando a possibilidade de utilização de outras fontes de energia, inclusive aproveitamento do biogás gerado no tratamento do lodo.

Apesar do lodo não ter sido um gargalo do processo, deve ser dada atenção a este resíduo pelo seu potencial poluidor, principalmente pela sua disposição em aterro e os efeitos causados pela degradação da matéria orgânica (lixiviado, emissões, etc.). Na busca pela sustentabilidade das estações, deve-se reduzir o volume gerado, bem como avaliar o tratamento e disposição desse material.

\section{REFERÊNCIAS}

GUINEÉ, J. et al. Life Cycle Assessment: Past, Present, and Future. Environ. Sci. Technol. 2011, 45, 90-96.

COROMINAS, L. et al. Life cycle assessment applied to wastewater treatment: State of the art. Water Research, v. 47, n. 15, p. 5480-5492, 2013.

DAUDT, Gilberto Caye. Desempenho e emissões de óxido nitroso de reator em bateladas sequenciais com grânulos aeróbios para tratamento de esgoto sanitário. 2015. 141 f. Dissertação (Mestrado) - Curso de Engenharia Federal de Santa Catarina, Florianópolis, 2015. 